OPEN ACCESS

Edited by:

Daniel P. Bailey,

University of Bedfordshire, United

Kingdom

Reviewed by:

Gianluca Vernillo,

University of Calgary, Canada

Tatiana Moro,

University of Texas Medical Branch,

United States

*Correspondence:

Gabriel A. Koepp

koepp.gabrie/@mayo.edu

Specialty section:

This article was submitted to

Exercise Physiology,

a section of the journal

Frontiers in Physiology

Received: 30 January 2017 Accepted: 02 May 2017 Published: 18 May 2017

Citation:

Koepp GA, Moore G and Levine JA

(2017) An Under-the-Table

Leg-Movement Apparatus and

Changes in Energy Expenditure.

Front. Physiol. 8:318.

doi: 10.3389/fphys.2017.00318

\section{An Under-the-Table Leg-Movement Apparatus and Changes in Energy Expenditure}

\author{
Gabriel A. Koepp ${ }^{1 *}$, Graham Moore ${ }^{1}$ and James A. Levine ${ }^{1,2}$ \\ ${ }^{1}$ Obesity Solutions, Mayo Clinic, Scottsdale, AZ, United States, ${ }^{2}$ Obesity Solutions, Arizona State University, Tempe, AZ, \\ United States
}

Introduction: Deskwork contributes substantially to sedentariness. Here, we evaluated an under-the-table apparatus that was designed to promote leg movement (fidgeting) while seated. Our hypothesis was that the under-the-table apparatus would increase energy expenditure.

Methods: We measured energy expenditure and heart rate in 26 people while they sat and worked using a standard chair, walked on a treadmill, and sat and worked using an under-the-desk apparatus that encouraged leg movement.

Results: Energy expenditure increased significantly while using the under-the-table apparatus when compared to the standard office chair (standard chair, $81 \pm 18 \mathrm{kcal} / \mathrm{h}$; under-the-table apparatus, $96 \pm 23 \mathrm{kcal} / \mathrm{h})(P<0.001)$; representing an $18 \pm 16 \%$ increase. The changes in energy expenditure were not as great as walking ( $1 \mathrm{mph}, 168$ $\pm 46 \mathrm{kcal} / \mathrm{h}, P<0.001 ; 2 \mathrm{mph}, 205 \pm 51 \mathrm{kcal} /, P<0.001)$, representing $107 \pm 37 \%$ and $155 \pm 48 \%$ increases over baseline, respectively.

Conclusions: An under-the-table apparatus that promotes leg movement can increase energy expenditure by approximately $20 \%$. Dynamic sitting is promoted by this apparatus and may be among a lexicon of options to help people move more while seated at work.

Keywords: energy expenditure, fidget, non-exercise activity thermogenesis, sedentary behavior, sitting disease

\section{INTRODUCTION}

Sitting excessively, as occurs with any desk-bound job, is associated with increased rates of obesity, impaired cognition, and numerous other chronic diseases (Dunstan et al., 2011; Thyfault et al., 2014; Falck et al., 2016). The majority of adults' weekly waking hours are spent at work, which is invariable sedentary (McCrady and Levine, 2009). Hence, solutions to reverse work-time sitting and encourage daily movement (non-exercise activity thermogenesis [NEAT]) are necessary (Levine, 2010).

Excessive sitting can, in part, be attributed to the computer-based nature of modern work and to the standard office design, both of which encourage employees to remain seated throughout the workday (McCrady and Levine, 2009). Walking or standing while at work are 2 possible solutions for disrupting total workplace sitting time (Dempsey et al., 2016); however, these options are often not practical (Judice et al., 2015; Levin and Chisholm, 2016) because leaving a workstation or office can hinder workflow (Stengard et al., 2016). New methods are needed to help sedentary workers move more. 
One approach to decreasing workplace sitting is to transform sitting into an active behavior, termed dynamic sitting. Laboratory studies have shown that people who fidget (move) while sitting increase energy expenditure by up to $10 \%$ more than those who do not (Levine et al., 2000). In one example of dynamic sitting, office chairs are replaced with large rubber balls (exercise stability ball) (Marks et al., 2012) so that a worker has to continuously fine-tune his or her balance and trunk musculature to maintain posture. Another dynamic sitting solution, such as with the apparatus we tested, is to encourage fidgeting and/or leg movements while seated (Pynt, 2015).

Walking, even slowly, doubles energy expenditure (Bouten et al., 1996; Westerterp et al., 1996); however, sitting, in general, is not exothermic ( $0-10 \%$ increase above basal metabolic rate) (Bouten et al., 1996; Westerterp et al., 1996). Here, we examine whether a commercial apparatus that promotes dynamic sitting can increase energy expenditure and heart rate above resting values. We compared these values to low-speed walking, which is known to improve overall health (Buckley et al., 2015). We hypothesized that the under-the-table dynamic-sitting apparatus we tested was associated with increased energy expenditure compared to sitting in a standard office chair. Because exercise is associated with increased heart rate, which in turn is linked to decreased morbidity and mortality (Chave et al., 1978; Pratley et al., 2000), we assessed the impact of the under-the-table dynamic-sitting apparatus on heart rate as well.

\section{PARTICIPANTS AND METHODS}

\section{Participants}

Participants provided informed written consent and the Mayo Clinic Institutional Review Board approved the protocol. Twenty-six participants (14 women and 12 men) were included with a mean $( \pm S D)$ age of $23 \pm 5$ years and a body mass index (BMI) of $26 \pm 5.5 \mathrm{~kg} / \mathrm{m}^{2}$.

\section{Standard Office Chair}

The criterion model chair (the "control chair") used is a standard office chair (Steelcase, Grand Rapids, MI).

\section{Under-the-Table Leg-Movement Apparatus}

The HOVR (Active Ideas LLC, Chicago, IL) is a pendulum attached to the underside of a desk or a portable stand. At the end of the pendulum are two discs mounted on an adjustable balanced beam (Figure 1).

\section{Attachment to the Pre-existing Desk}

At the top of the pendulum is a dense plastic clip. The clip is hung from a metal hook on the bottom side of the desk or $40-\mathrm{cm}$ portable stand designed to fit under a standard office desk. The fastener mounted to the underside of the desk is securely attached with 4 screws. The pendulum may be moved up and down, forward and backward to achieve the user's desired position for both attachment options. In this study, the under-the-desk mount was used.

The pendulum is constructed from a 5-cm-wide nylon webbed strap and is adjustable from approximately 20 to $70 \mathrm{~cm}$. At the

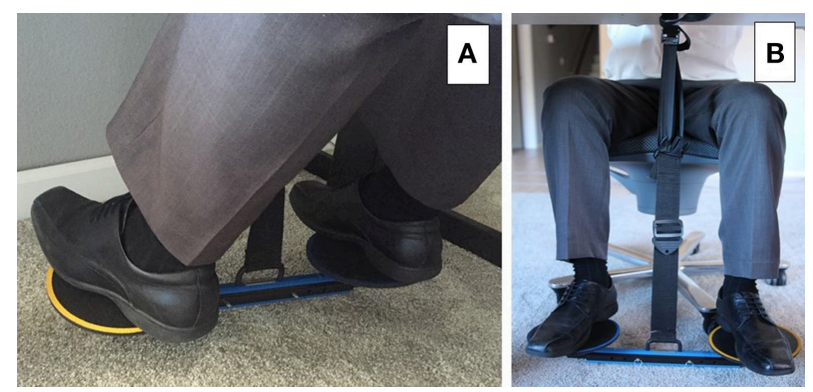

FIGURE 1 | Under-the-table leg-movement apparatus (A,B).

bottom of the pendulum is another dense plastic clip, identical to one at the top. This clip is fastened to a metal pin $(3.5-\mathrm{cm}$ long and $0.5-\mathrm{cm}$ in diameter). The metal pin is the fulcrum for the adjustable balanced beam and discs (Figure 1).

The balanced beam is constructed from dense plastic and rubber. It is adjustable to 37,42 , and $47 \mathrm{~cm}$ with 2 screws to accommodate users' varying sizes and preferences. At each end of the balance beam, identical $16-\mathrm{cm}$ diameter metal discs are mounted with "ball and socket" metal hardware that allows for approximately $20^{\circ}$ of motion in any direction relative to the position of the balance beam. The edge (circumference) and the top of the disc are covered by rubber to add a greater friction coefficient, which prevents the participant's feet from slipping. The discs also spin freely on the z-axis to allow leg movement without needing to readjust the feet (Figure 1).

\section{Protocol}

Prior to testing, participants were shown the equipment and the experimental protocol was explained. Body composition, height, weight, and blood pressure were all measured. Participants confirmed that they had not consumed any food or beverage aside from water in the $2 \mathrm{~h}$ preceding testing. Patients then rested, sitting comfortably at rest in a shaded quiet room for $30 \mathrm{~min}$. They were not permitted to speak, eat, or use mobile devices during testing.

Participants were tested in thermal comfort $\left(25.2 \pm 0.7^{\circ} \mathrm{C}\right.$, $956.9+1.8 \mathrm{mBar}$ barometric pressure, and $57.0+2.1 \%$ humidity).

Sitting energy expenditure and heart rate were measured for 20 min via indirect calorimetry. During this time, participants worked at a computer and sat on a standard office chair (Criterion; Steelcase, Grand Rapids, MI) in an effort to simulate their normal work activity. Data for the first 2 and final $2 \mathrm{~min}$ were excluded. Following this, subjects rested for 20 min while sitting (not working).

For the next timed interval, participants used the under-thetable dynamic-sitting apparatus while working at the computer. As with the previous segment, energy expenditure and heart rate were measured for $20 \mathrm{~min}$, and data for the first 2 and final $2 \mathrm{~min}$ were excluded. Participants again rested in a sitting position for 20 min following testing. 
Finally, participants were asked to walk on a calibrated treadmill (4Front; Woodway, Waukesha, WI) at $1 \mathrm{mph}$ and $2 \mathrm{mph}$, each for $20 \mathrm{~min}$. These speeds were thought to be comparable to the rates of people walking while at work (Ben-Ner et al., 2014). Energy expenditure and heart rate were measured throughout the walks, and data for the first 2 and final 2 min of each velocity were excluded.

The order of the sitting and walking phases were not randomized. This was to avoid the effect of high energy expenditure (as occurs after walking) on lower exertion measurements (e.g., fidgeting). This approach was used when measuring small changes in energy expenditure (Levine et al., 1999, 2000)

\section{METHODS}

\section{Body Composition}

Participants' body composition and weight were measured using a calibrated Seca Medical Body Composition Analyzer 514 (Seca, Hamburg, Germany) (Heymsfield et al., 2000) while they were wearing light clothing (athletic shorts and t-shirt); height (without shoes) was measured using a Seca 217 stadiometer (Seca, Hamburg, Germany).

\section{Energy Expenditure}

Energy expenditure was measured using indirect calorimetry (Metamax 3B; Cortex, Leipzig, Germany) (Levine et al., 2000). The calorimeter was calibrated using $5.0 \% \quad \mathrm{CO}_{2} \quad \begin{array}{lll}15.0 \% & \mathrm{O}_{2}\end{array}$ balance nitrogen (Praxair Inc., Danbury, CT) and ambient air according to the manufacturer's specifications. In addition, the calorimeter was volume calibrated before each participant using a $3 \mathrm{~L}$ syringe. The calorimeter was able to collect breath-bybreath $\mathrm{CO}_{2}$ and $\mathrm{O}_{2}$ production and consumption, respectively, and energy expenditure was calculated using standard formulae (Weir, 1949).

\section{Heart Rate Monitoring}

Participants were also fitted with a Polar Heart Rate Monitor H7 (Polar Inc., Lake Success, NY). Heart rate samples were synchronized and recorded for each breath.

\section{Statistical Analysis}

Analysis of data with repeated measures needs to consider the covariance structure due to correlations between repeated measures across time or different conditions on each participant. Failure to properly take care of this issue could result in biased estimates. The univariate analysis of variance (ANOVA) assumes equal variances or correlations across time or conditions on each participant, and this might not be true. In many cases, participant correlations tend to decrease with increasing lag time between measures. To overcome this limitation of univariate ANOVA, the general linear mixed model is used in this manuscript. This model allows for different correlations between measures.

For analysis, the PROC MIXED with REPEATED statement was used in SAS (SAS Institute Inc., Cary, NC). The model assumed no specific variance-covariance structure (unstructured) based on Akaike Information Criterion values and $-2 \log$ likelihood scores of 4 models (unstructured, compound symmetry, auto-regressive, and auto-regressive heterogeneous variance-covariance). The original data in wide format consisted of 26 participants ( 14 women, 12 men), and 2 outcomes (energy expenditure and heart rate) were measured under 5 different conditions for each participant. The data were transposed to a long format for the linear mixed model, and total available sample size for analysis was 130 person-conditions (26 individuals $\times 5$ conditions).

\section{RESULTS}

Participants tolerated the protocol without complaint. Anthropometric and body composition data are shown in Table 1. Four additional participants were studied (3 women, 1 man), but their data are not included in the analysis because it was incomplete due to technical failures. Omitting these 4 subjects did not influence the principal conclusion because, in all 4 cases, energy expenditure increased using the under-the-table dynamic-sitting apparatus.

Twenty-three of the participants reported that their jobs were sedentary in nature, whereas the remaining 3 reported having employment that necessitated a degree of movement throughout

TABLE 1 | Demographic and body composition information for 26 study volunteers ${ }^{a}$.

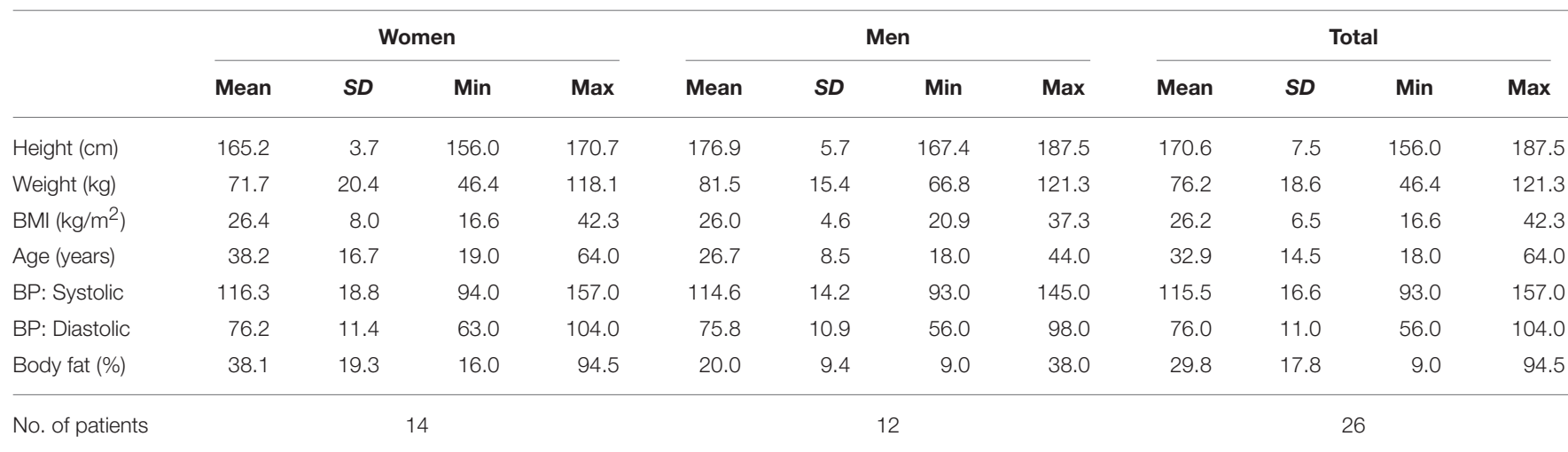

${ }^{a}$ Body fat was measured using bioelectrical impedance (Falck et al., 2016).

$B M I$, body mass index; BP, blood pressure; SD, standard deviation. 
TABLE 2 | Energy expenditure and heart rate by sex.

\begin{tabular}{|c|c|c|c|c|c|c|}
\hline \multirow[t]{3}{*}{ Phase } & \multicolumn{3}{|c|}{ Energy expenditure (kcal per h) } & \multicolumn{3}{|c|}{ Heart rate (bpm) } \\
\hline & Women & Men & Total & Women & Men & Whole group \\
\hline & Mean $\pm S D$ & Mean $\pm S D$ & Mean $\pm S D$ & Mean $\pm S D$ & Mean $\pm S D$ & Mean $\pm S D$ \\
\hline Sitting & $69.7 \pm 12.8$ & $94.5 \pm 14.2$ & $81.2 \pm 18.2$ & $71.2 \pm 8.6$ & $75.7 \pm 15.9$ & $73.2 \pm 12.4$ \\
\hline Using apparatus & $81.7 \pm 17.9^{a}$ & $112.1 \pm 116.1^{a}$ & $95.7 \pm 22.8^{a}$ & $73.4 \pm 9.0^{\mathrm{a}}$ & $77.6 \pm 17.6$ & $75.3 \pm 13.6^{a}$ \\
\hline Walking at $1 \mathrm{mph}$ & $150.8 \pm 43.8^{a, b}$ & $187.0 \pm 42.5^{a, b}$ & $167.5 \pm 46.1^{a, b}$ & $87.2 \pm 13.4^{a, b}$ & $94.0 \pm 41.4^{a, b}$ & $90.3 \pm 29.3^{a, b}$ \\
\hline Walking at 2 mph & $186.8 \pm 55.4^{a, b, c}$ & $225.9 \pm 35.8^{a, b, c}$ & $204.9 \pm 50.5^{a, b, c}$ & $88.7 \pm 13.4^{a, b}$ & $101.3 \pm 51.2^{a, b}$ & $94.5 \pm 35.9^{a, b, c}$ \\
\hline Walking at 3 mph & $261.4 \pm 87.6^{a, b, c, d}$ & $294.3 \pm 48.6^{a, b, c, d}$ & $276.6 \pm 72.8^{a, b, c, d}$ & $106.1 \pm 17.7^{a, b, c, d}$ & $115.7 \pm 73.6^{a, b, c, d}$ & $110.6 \pm 50.7^{a, b, c, d}$ \\
\hline
\end{tabular}

a Significantly different from "sitting" condition at the P-value 0.05 level.

"Significantly different from "surfing" condition at the P-value 0.05 level.

"Significantly different from "1 mph" condition at the P-value 0.05 level.

"Significantly different from "2 mph" condition at the P-value 0.05 level. "Apparatus" refers to the apparatus to promote leg movement. SD, standard deviation.

the workday. Of the 23 participants, 7 self-reported as being sedentary, 12 as being moderately active, and 6 as exercising regularly.

Energy expenditure for the 2 seated conditions (standard chair and under-the-table dynamic-sitting apparatus) and slow walking (1 and $2 \mathrm{mph}$ ) are shown in Tables 2, 3. Energy expenditure while sitting in a standard chair showed a positive correlation with body weight $(r=0.55, P=0.003)$. The relationship was described by the following equation: 39.7.

Sitting energy expenditure $(\mathrm{kcal} / \mathrm{hr})=0.544 \times$ weight $(\mathrm{kg})+$

Energy expenditure increased considerably while using the under-the-table dynamic-sitting apparatus when compared to a standard office chair (Tables 2, 3). Energy expenditure increased in 25 of 26 participants, from a mean of $81 \pm 18 \mathrm{kcal} / \mathrm{hr}$ to $96 \pm 23$ $\mathrm{kcal} / \mathrm{h}(P<0.001)$, representing a mean increase of $18.4 \pm 16.2 \%$. There was a strong association between energy expenditure while sitting on a standard chair and energy expenditure using the under-the-table leg-movement apparatus $\left(r^{2}=0.76 ; P<0.001\right)$. Heart rate did not increase substantially when using the underthe-table leg-movement apparatus compared to sitting on a standard office chair without the apparatus $(73 \pm 12$ cf $75 \pm 14$ beats/min) (Figure 2).

Changes in energy expenditure for the under-the-table legmovement apparatus vs. the standard office chair were not as great as for walking at a speed of 1 or $2 \mathrm{mph}$ (Tables 2,3 ). The changes in energy expenditure were $15 \pm 11 \mathrm{kcal} / \mathrm{hr}$ for the under-the-table leg-movement apparatus, $86 \pm 24 \mathrm{kcal} / \mathrm{hr}$ for walking at $1 \mathrm{mph}$, and $124 \pm 39 \mathrm{kcal} / \mathrm{hr}$ for walking at $2 \mathrm{mph}$. Slow walking at 1 and $2 \mathrm{mph}$ were associated with significant increases in heart rate (rest, $73 \pm 12 \mathrm{bpm} ; 1 \mathrm{mph}, 90 \pm 36 \mathrm{bpm}$; $[P<0.001]$; and $2 \mathrm{mph}, 111 \pm 51 \mathrm{bpm}[P<0.001])$ when compared to sitting in a standard office chair.

The results show that there is a significant difference in the overall level of energy expenditure between men and women $(P$ $=0.04$ ). However, these differences disappear after body weight is accounted for (Table 3). There were no differences in the overall heart rate level between men and women. However, there is a considerable conditioning effect whereby heart rate increased with walking, as was expected.
TABLE 3 | Energy expenditure and heart rate by weight and sex.

\begin{tabular}{llll}
\hline & \multicolumn{3}{c}{ Energy Expenditure (kcal/h/kg) } \\
\cline { 2 - 4 } & \multicolumn{1}{c}{ Women } & \multicolumn{1}{c}{ Men } & \multicolumn{1}{c}{ Total } \\
\cline { 2 - 4 } Phase & Mean $\pm \mathbf{S D}$ & Mean $\pm \mathbf{S D}$ & Mean $\pm \mathbf{S D}$ \\
\hline Sitting & $1.0 \pm 0.2$ & $1.2 \pm 0.2$ & $1.1 \pm 0.2$ \\
Using apparatus & $1.2 \pm 0.2^{\mathrm{a}}$ & $1.4 \pm 0.2^{\mathrm{a}}$ & $1.3 \pm 0.2^{\mathrm{a}}$ \\
$1 \mathrm{mph}$ & $2.1 \pm 0.3^{\mathrm{a}, \mathrm{b}}$ & $2.3 \pm 0.3^{\mathrm{a}, \mathrm{b}}$ & $2.2 \pm 0.3^{\mathrm{a}, \mathrm{b}}$ \\
$2 \mathrm{mph}$ & $2.6 \pm 0.3^{\mathrm{a}, \mathrm{b}, \mathrm{c}}$ & $2.8 \pm 0.2^{\mathrm{a}, \mathrm{b}, \mathrm{c}}$ & $2.7 \pm 0.3^{\mathrm{a}, \mathrm{b}, \mathrm{c}}$ \\
$3 \mathrm{mph}$ & $3.6 \pm 0.3^{\mathrm{a}, \mathrm{b}, \mathrm{c}, \mathrm{d}}$ & $3.6 \pm 0.3^{\mathrm{a}, \mathrm{b}, \mathrm{c}, \mathrm{d}}$ & $3.6 \pm 0.3^{\mathrm{a}, \mathrm{b}, \mathrm{c}, \mathrm{d}}$ \\
\end{tabular}

a significantly different from "sitting" condition at the P-value 0.05 level. ${ }^{b}$ Significantly different from "surfing" condition at the $P$-value 0.05 level. "Significantly different from "1 mph" condition at the P-value 0.05 level. "Significantly different from "2 mph" condition at the P-value 0.05 level. "Apparatus" refers to the apparatus to promote leg movement. SD, standard deviation.

\section{DISCUSSION}

Excessive sitting is linked with chronic disease, impaired cognition, and obesity (Dunstan et al., 2011; Thyfault et al., 2014; Falck et al., 2016). The majority of adults' weekly waking hours are spent at work, which is invariable sedentary (McCrady and Levine, 2009). Hence, solutions to considerably decrease work-time sitting and encourage daily movement are necessary. In this study, we found that when a person sat and used an under-the-table dynamic-sitting apparatus, energy expenditure increased by about $20 \%$. Heart rate, however, did not increase substantially. The reason for this is that the movement promoted by the under-the-table apparatus is sufficient to increase energy expenditure through leg muscle activity, but not sufficiently intense enough to accelerate heart rate markedly (Levine et al., 2000). It is not surprising that energy expenditure increased significantly based on leg movements alone because glutealfemoral muscular contractions contribute substantially to human energy expenditure (Westerterp et al., 1996; Westerterp and Bouten, 1997). What is important to note is that these types of movements may directly impact glycemic control and other 


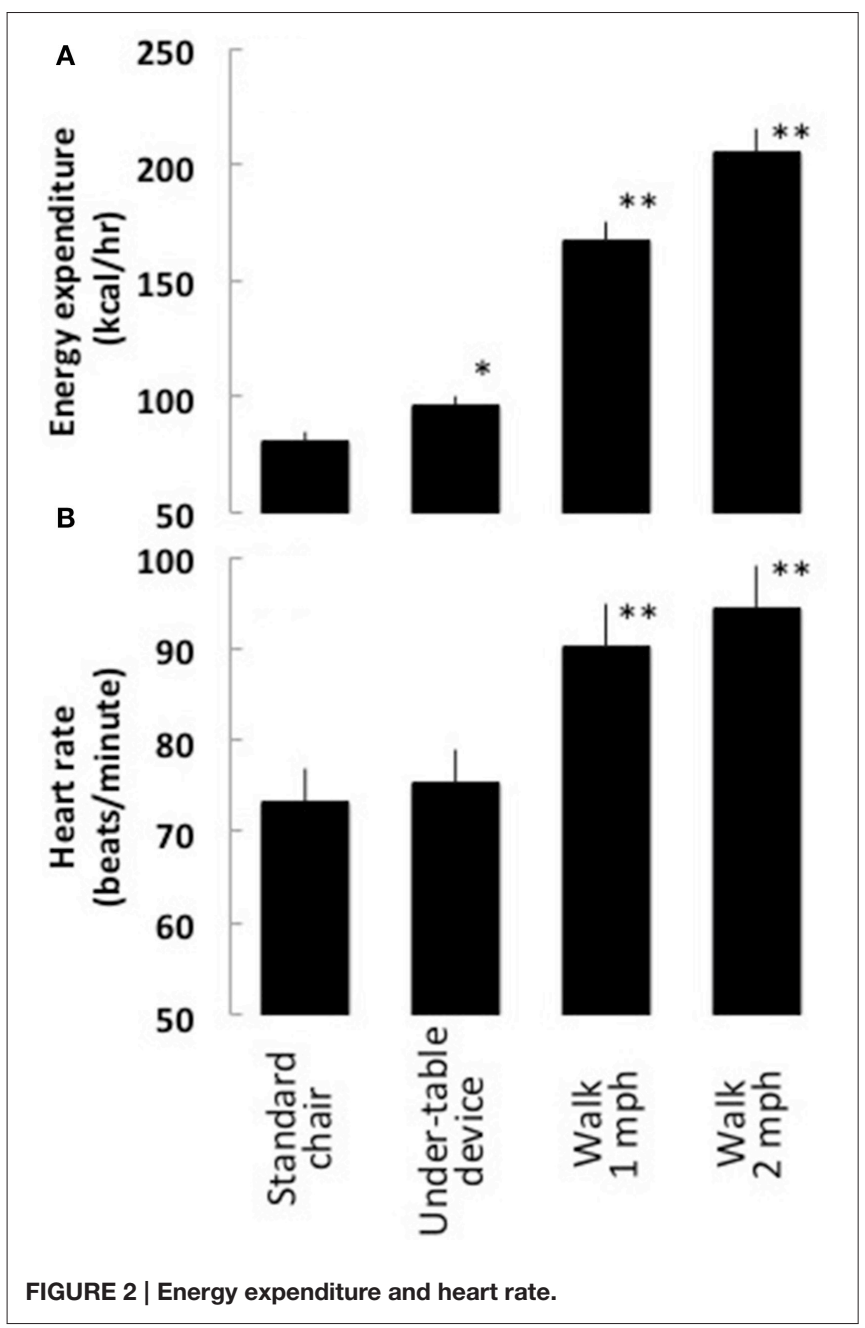

health outcomes (Kadam and Chuan, 2016; Dempsey et al., 2017; Fanchamps et al., 2017; Larsen et al., 2017) although we did not measure these outcomes. The under-the-table dynamic-sitting apparatus we tested was exothermic but unlikely to contribute to aerobic fitness. Noting that heart rate did not increase with the use of the under-the-table dynamic-sitting apparatus it could be assumed that such a device doesn't contribute to physical fitness. It may not. However, it is possible that by using the under-the-table dynamic-sitting apparatus a person becomes more active throughout their day and daily physical activity increases. However, this was not tested here. Other studies show

\section{REFERENCES}

Ben-Ner, A., Hamann, D. J., Koepp, G., Manohar, C. U., and Levine, J. (2014). Treadmill workstations: the effects of walking while working on physical activity and work performance. PLoS ONE 9:e88620. doi: 10.1371/journal.pone.0088620

Bouten, C. V., Verboeket-van de Venne, W. P., Westerterp, K. R., Verduin, M., and Janssen, J. D. (1996). Daily physical activity assessment: comparison between movement registration and doubly labeled water. J. Appl. Physiol. 81, 1019-1026. that office furniture, such as treadmill desks, can promote NEAT and daily activity (Koepp et al., 2013; Ben-Ner et al., 2014). These approaches, while expensive, have improved health care outcomes and workplace productivity (Koepp et al., 2013; BenNer et al., 2014). Active work has the potential to improve overall health.

\section{LIMITATIONS}

Our study had several limitations. As this was a laboratory study conducted only to examine the effects of an apparatus on energy expenditure and heart rate, we did not examine whether the apparatus would impact productivity (positively or negatively), health outcomes, or standing time; these would be goals of future studies. There is solid evidence that breaking up sitting time can benefit glycemic variables (Dunstan et al., 2012). We did not examine whether the apparatus we studied could benefit blood glucose; this too would be a beneficial future study. Similarly, more time spent walking is known to improve overall health (Levine, 2007). It would be interesting to assess whether using a dynamic-sitting apparatus could help increase daily walking. In spite of these limitations, these experiments are encouraging. It would be worthwhile to examine dynamic-sitting interventions in real-world offices.

\section{CONCLUSIONS}

In conclusion, new approaches are needed to help decrease excessive sitting and the poor health linked with this prolonged lack of physical activity. Here, we have shown that an under-the-table dynamic-sitting apparatus can improve energy expenditure while a person sits. The applicability of such an apparatus in real-world offices remains to be seen.

\section{AUTHOR CONTRIBUTIONS}

GK was responsible for study design, IRB approvals, patient recruitment, data collection, data analysis, and manuscript preparation. JL was responsible for study design, IRB approvals, data analysis, and manuscript preparation. GM was responsible for data collection and data analysis.

\section{FUNDING}

Funds to complete this study were provided by Mayo Clinic Foundation.

Buckley, J. P., Hedge, A., Yates, T., Copeland, R. J., Loosemore, M., and Hamer, M. (2015). The sedentary office: an expert statement on the growing case for change towards better health and productivity. Br. J. Sports Med. 49, 1357-1362. doi: 10.1136/bjsports-2015-094618

Chave, S. P., Morris, J. N., Moss, S., and Semmence, A. M. (1978). Vigorous exercise in leisure time and the death rate: a study of male civil servants. J. Epidemiol. Commun. Health 32, 239-243. doi: 10.1136/jech.32.4.239

Dempsey, P. C., Grace, M. S., and Dunstan, D. W. (2017). Adding exercise or subtracting sitting time for glycaemic control: where do we stand? Diabetologia 60, 390-394. doi: 10.1007/s00125-016-4180-4 
Dempsey, P. C., Larsen, R. N., Sethi, P., Sacre, J. W., Straznicky, N. E., Cohen, N. D., et al. (2016). Benefits for Type 2 Diabetes of Interrupting prolonged sitting with brief bouts of light walking or simple resistance activities. Diabetes Care 39, 964-972. doi: 10.2337/ dc15-2336

Dunstan, D. W., Kingwell, B. A., Larsen, R., Healy, G. N., Cerin, E., Hamilton, M. T., et al. (2012). Breaking up prolonged sitting reduces postprandial glucose and insulin responses. Diabetes Care 35, 976-983. doi: 10.2337/dc11-1931

Dunstan, D. W., Thorp, A. A., and Healy, G. N. (2011). Prolonged sitting: is it a distinct coronary heart disease risk factor? Curr. Opin. Cardiol. 5, 412-419. doi: 10.1097/hco.0b013e3283496605

Falck, R. S., Davis, J. C., and Liu-Ambrose, T. (2016). What is the association between sedentary behaviour and cognitive function? A systematic review. $\mathrm{Br}$. J. Sports Med. 51, 759-759. doi: 10.1136/bjsports-2015-095551

Fanchamps, M. H., van den Berg-Emons, H. J., Stam, H. J., and Bussmann, J. B. (2017). Sedentary behavior: different types of operationalization influence outcome measures. Gait Posture 54, 188-193. doi: 10.1016/j.gaitpost.2017.02.025

Heymsfield, S. B., Nunez, C., Testolin, C., and Gallagher, D. (2000). Anthropometry and methods of body composition measurement for research and field application in the elderly. Eur. J. Clin. Nutr. 54 (Suppl. 3), S26-S32. doi: 10.1038/sj.ejcn.1601022

Judice, P. B., Hamilton, M. T., Sardinha, L. B., and Silva, A. M. (2015). Randomized controlled pilot of an intervention to reduce and break-up overweight/obese adults' overall sitting-time. Trials 16:490. doi: 10.1186/s13063-015-1015-4

Kadam, P. D., and Chuan, H. H. (2016). Erratum to: rectocutaneous fistula with transmigration of the suture: a rare delayed complication of vault fixation with the sacrospinous ligament. Int. Urogynecol. J. 27:505. doi: 10.1007/s00192-016-2952-5

Koepp, G. A., Manohar, C. U., McCrady-Spitzer, S. K., Ben-Ner, A., Flint-Paulson, D., Runge, C. F., et al. (2013). Treadmill desks: a 1-year prospective trial. Obesity 2013, 705-711. doi: 10.1002/oby.20121

Larsen, R. N., Dempsey, P. C., Dillon, F., Grace, M., Kingwell, B. A., Owen, N., et al. (2017). Does the type of activity 'break' from prolonged sitting differentially impact on post-prandial blood glucose reductions? An exploratory analysis. Appl. Physiol. Nutr. Metab. doi: 10.1139/apnm-2016-0642. [Epub ahead of print].

Levin, C., and Chisholm, D. (2016). "Cost-effectiveness and affordability of interventions, policies, and platforms for the prevention and treatment of mental, neurological, and substance use disorders," in Vol. 4, 3rd Edn., eds V. Patel, D. Chisholm, T. Dua, R. Laxminarayan, M. E. Medina-Mora (Washington, DC: International Bank for Reconstruction and Development/The World Bank), 219-236.

Levine, J. A. (2007). Exercise: a walk in the park? Mayo Clin. Proc. 82, 797-798. doi: $10.4065 / 82.7 .797$

Levine, J. A. (2010). Health-chair reform: your chair: comfortable but deadly. Diabetes 59, 2715-2716. doi: 10.2337/db10-1042
Levine, J. A., Baukol, P. A., and Pavlidis, Y. (1999). The energy expended chewing gum. N. Engl. J. Med. 341:2100. doi: 10.1056/nejm199912303412718

Levine, J. A., Schleusner, S. J., and Jensen, M. D. (2000). Energy expenditure of nonexercise activity. Am. J. Clin. Nutr. 72, 1451-1454.

Marks, C. R., Dupuie, L., and Patros, J. (2012). Stability ball sitting elevates peak arm ergometry oxygen consumption and heart rate. Int. J. Exerc. Sci. 5, 360-366.

McCrady, S. K., and Levine, J. A. (2009). Sedentariness at work: how much do we really sit? Obesity 17, 2103-2105. doi: 10.1038/oby.2009.117

Pratley, R. E., Hagberg, J. M., Dengel, D. R., Rogus, E. M., Muller, D. C., and Goldberg, A. P. (2000). Aerobic exercise training-induced reductions in abdominal fat and glucose-stimulated insulin responses in middle-aged and older men. J. Am. Geriatr. Soc. 48, 1055-1061. doi: 10.1111/j.1532-5415.2000.tb04780.x

Pynt, J. (2015). Rethinking design parameters in the search for optimal dynamic seating. J. Bodyw. Mov. Ther. 19, 291-303. doi: 10.1016/j.jbmt.2014.07.001

Stengard, J., Bernhard-Oettel, C., Berntson, E., Leineweber, C., and Aronsson, G. (2016). Stuck in a job: being "locked-in" or at risk of becoming lockedin at the workplace and well-being over time. Work Stress 30, 152-172. doi: 10.1080/02678373.2016.1163804

Thyfault, J. P., Du, M., Kraus, W. E., Levine, J. A., and Booth, F. W. (2014). Physiology of sedentary behavior and its relationship to health outcomes. Med. Sci. Sports Exerc. 47, 1301-1305. doi: 10.1249/MSS.0000000000 000518

Weir, J. B. (1949). New methods for calculating metabolic rate with special reference to protein metabolism. Nutrition 6, 213-221. doi: 10.1113/jphysiol.1949.sp004363

Westerterp, K. R., and Bouten, C. V. (1997). Physical activity assessment: comparison between movement registration and doubly labeled water method. Z. Ernahrungswiss 36, 263-267. doi: 10.1007/BF01 617795

Westerterp, K. R., Verboeket-van de Venne, W. P., Bouten, C. V., de Graaf, C., van het Hof, K. H., and Weststrate, J. A. (1996). Energy expenditure and physical activity in subjects consuming full-or reduced-fat products as part of their normal diet. Br. J. Nutr. 76, 785-795. doi: 10.1079/BJN199 60086

Conflict of Interest Statement: The authors declare that the research was conducted in the absence of any commercial or financial relationships that could be construed as a potential conflict of interest.

Copyright (c) 2017 Koepp, Moore and Levine. This is an open-access article distributed under the terms of the Creative Commons Attribution License (CC BY). The use, distribution or reproduction in other forums is permitted, provided the original author(s) or licensor are credited and that the original publication in this journal is cited, in accordance with accepted academic practice. No use, distribution or reproduction is permitted which does not comply with these terms. 